Article

\title{
Ecological Security Patterns Assessment of Liao River Basin
}

\author{
Chunli Zhao ${ }^{1,2,3} \mathbb{1}^{\circ}$, Chenxing Wang ${ }^{1,4}$, Yan Yan ${ }^{1, *}$, Peng Shan ${ }^{1,3}$, Jiaxun Li ${ }^{1,3}$ \\ and Jianguo Chen ${ }^{2}$ \\ 1 State Key Laboratory of Urban and Regional Ecology, Research Center for Eco-Environmental Sciences, \\ Chinese Academy of Sciences, Beijing 100085, China; chunli-zhao@163.com (C.Z.); \\ star881003@126.com (C.W.); shanpeng85@126.com (P.S.); jxli_st@rcees.ac.cn (J.L.) \\ 2 Department of Engineering Physics, Institute of Public Safety Research, Tsinghua University, \\ Beijing 100084, China; chenjianguo@tsinghua.edu.cn \\ 3 College of Resources and Environment, University of Chinese Academy of Sciences, Beijing 100049, China \\ 4 CITIC Guoan Group, Beijing 100020, China \\ * Correspondence: yyan@rcees.ac.cn; Tel.: +86-010-62849510
}

Received: 4 May 2018; Accepted: 6 July 2018; Published: 10 July 2018

\begin{abstract}
Ecological security assessment aims at identifying an ecosystem's stability, recognizing the ability to maintain ecological health under various scenarios of ecological risks. In this study, we focus on the ecological security of Liao River Basin not only in terms of directly considering the sustainable development of the basin itself but also in terms of its importance as part of an ecological macro-control for northeast China. We built a "structure-quality-process" analytical framework to assess the ecological security of Liao River Basin. Our results showed that (i) land conversion from cultivated to artificial surfaces represented a dramatic change occurring in the region; (ii) the requirements of regional sustainable development would not likely be satisfied in regard to the given ecosystem services provided by the basin due to poor spatial coordination capability; and (iii) the priority areas for optimizing the ecological security patterns of the basin include the upstream and the downstream regions. The "structure-quality-process" assessment framework provides a dynamic perspective of ecological security and also considers the relationships and functions of the internal structures and processes of the ecosystem. The optimization of ecosystem structures and processes is essential and forms the basic measures and key content of macro-control for well-structured ecological security patterns.
\end{abstract}

Keywords: Liao River Basin; ecological security; ecosystem service; ecological quality; ecosystem structure

\section{Introduction}

Anthropogenic activities and climatic changes have led to complicated changes in ecosystems at the regional scale, which bring significant losses and severe impacts to human society. Alteration in land use is likely to be a major driver for ecosystem changes and ecosystem services distribution, with urbanization typically being the main cause of land use change [1]. Urbanization affects ecosystems both within and outside of urban areas [2]. These aforementioned processes can induce the instability of ecosystems and ecosystem services supply, and can even result in some ecological security problems; as such, ecological security (ES) has gained considerable research interest in recent years. ES refers to the security of natural and semi-natural ecosystems, including embedded ecosystem integrity and health [3-5]. Thus, ecosystem security ensures a state of harmony between nature, humankind, and society, with the focus on safeguarding interactions in these components. Ecological security assessment (ESA) at a regional scale has emerged as an important manner in which to address 
the maintenance of regional sustainable development. Importantly, a comprehensive understanding of the effects of ecosystem changes and corresponding safety considerations is very important for establishing regional environmental management policies [6].

The ES of river basins forms an integral part of ES at regional and national levels. As the natural division of regions, basins are an important consideration for ecosystem assessment and management [7-9]. The basin-scale assessment, based on an integrity scale, should consider geographical characteristics as well as the spatial coordination of sub-basins.

Liao River Basin (LRB) is one of the seven major river basins in China; it bears two vital ecological development goals for this region: ecological conservation and economic development. The northwestern region of LRB is located in a key ecotone situated in-between areas of agriculture-animal husbandry in northern China, and an area known for its major industrial activity and commercial grain cultivation in the central-southern region. In recent years, severe ecological and environmental problems have been noted in LRB, including grassland degeneration, desertification, wetland degradation, and soil erosion. Consequently, the ES of this basin concerns the interactions of factors occurring in sub-basins at a regional scale, and it also influences macro-control and sustainable development of northeastern China [10]. This study evaluated ecosystem changes in LRB, and simultaneously assessed the ES based on the "structure-quality-process" framework. In this paper, we describe the framework employed and the methods and data used; we discuss the ecosystem changes and assessment of ES based on the "structure-quality-process" framework; and finally, we propose recommendations and possible amendments to existing policies.

\section{Assessment Methods and Data}

\subsection{Study Area}

This study was conducted in LRB, which is located in northeastern China, bordering Songhua River Basin to the north and Bohai Gulf to the south $\left(38^{\circ} 41^{\prime}-45^{\circ} 10^{\prime} \mathrm{N}\right.$ and $\left.116^{\circ} 31^{\prime}-128^{\circ} 17^{\prime} \mathrm{E}\right)$. The LRB has an area of $31.4 \times 10^{4} \mathrm{~km}^{2}$ and contains six sub-basins (Figure 1). The LRB terrain is lower in the southern and central regions and higher in the northern, eastern, and western regions.

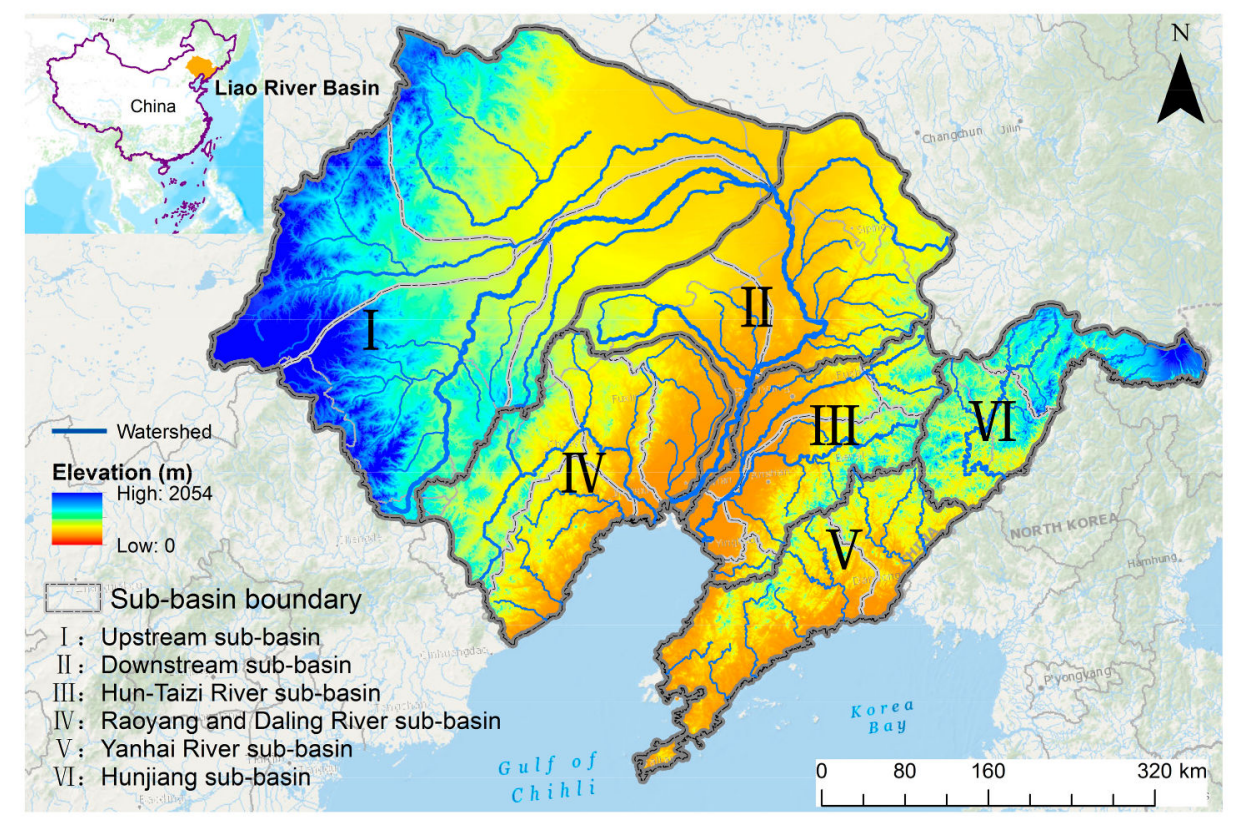

Figure 1. A geospatial overview of Liao River Basin.

On one hand, the upstream region in the basin has witnessed a substantial growth in animal husbandry and agriculture industries but has a relatively lower population density. On the other 
hand, the downstream region is an old primary industrial base in northeast China, with two rapidly developing regions-the central-south city group in Liaoning province and Shenyang Economic Zone-located in this area, and it has a relatively higher population density.

Recently, LRB has experienced rapid economic and social growth, and human activities (particularly land conversion and the use of natural resources) have also increasingly been having greater impacts on the regional environment. The study period of our research was 2000-2010.

\subsection{ESA Framework}

ES represents the security of natural and semi-natural ecological systems, and it embodies the completeness and health of environmental systems. The core of ES includes system integrity and instability [3-5]. It is necessary for ES to explore the interactions among various ecosystem processes. Regional ESA emphasizes the safety interactions between ecosystem structures and processes; the effects of these interactions manifest as processes generating structures and structures affecting processes, and there are interaction effects and feedback between the two [11,12]. Furthermore, in addition to considering the completeness and health of natural ecology systems, ES also considers the security of human survival and development, which is reflected in natural ecological systems providing support to human existence and sustainable development.

Based on our current comprehension of the specific ecological functions and processes necessary for landscape pattern maintenance [13-16], and the interactions between ecosystem processes and structures, we built a "structure-quality-process" framework to explore the ecological security pattern (ESP) in LRB (Figure 2).

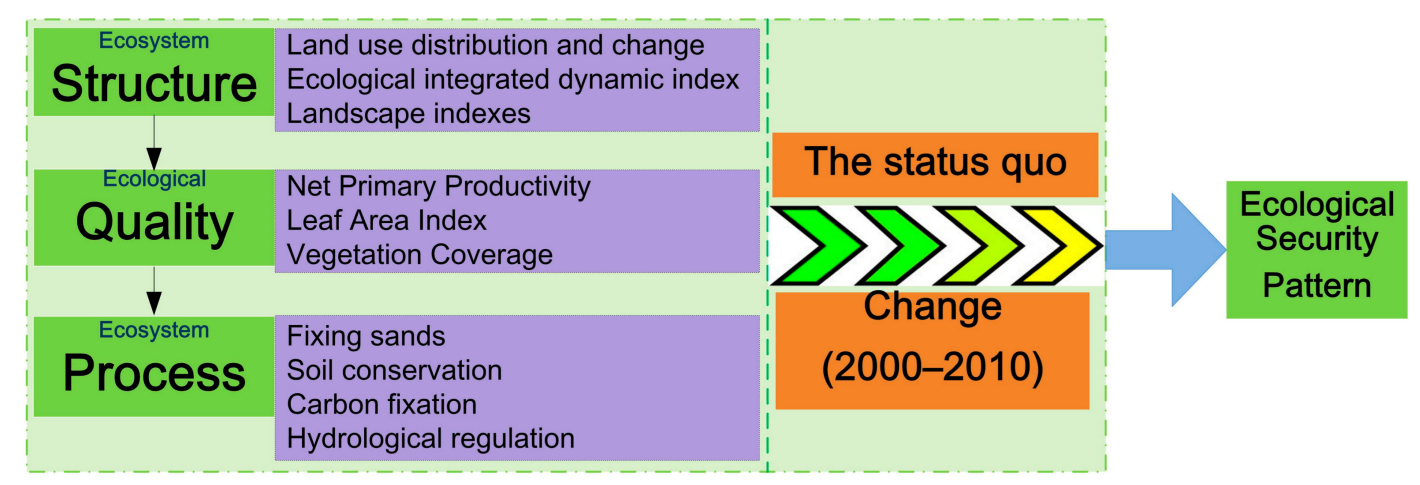

Figure 2. Framework of ecological security pattern for Liao River Basin.

Ecological structure refers to the type, number, spatial distribution, and configuration of an ecosystem or landscape patch at the macro-scale. Ecological structure is closely related to ecosystem processes at various scales, and it has profound impacts on the ability of an ecosystem to resist impacts, as well as an ecosystem's resilience, system stability, and biodiversity [11,12,17]. In general, ecological structure and changes are described by ecosystem structural changes and regional differences $[18,19]$. In this study, we used indexes such as land use distribution and change, ecological integrated dynamic index [20], and other basic landscape indexes to describe the ecosystem structure in LRB.

Ecological quality is identified as the relationship between environmental requirements and accomplishment of functions, or as a translation of the ecosystem situations [21]. We used indexes such as Net Primary Productivity (NPP), Leaf Area Index (LAI), and Vegetation Coverage (VC) to independently evaluate the quality of the cultivated land, forests, and grasslands, which collectively account for about $90 \%$ of the region's areas, and graded ecosystem quality by scoring performed by experts in the field (Table 1). 
Table 1. Grading of ecosystem quality.

\begin{tabular}{cccccccc}
\hline & Unit & Land Type & Lower & Low & Middle & High & Higher \\
\hline LAI & - & Forest & $0-0.5$ & $0.5-1$ & $1-2$ & $2-5$ & $5-\infty$ \\
VC & $\%$ & Grass land & $0-20$ & $20-40$ & $40-60$ & $60-80$ & $80-100$ \\
NPP & $\mathrm{Mg} \cdot \mathrm{C} / \mathrm{ha} \cdot \mathrm{yr}$ & Cultivated land & $0-6$ & $6-12$ & $12-18$ & $18-24$ & $24-\infty$ \\
\hline
\end{tabular}

Note: LAI, VC, and NPP are abbreviations for Leaf Area Index, Vegetation Coverage, and Net Primary Productivity, respectively.

Ecological process refers to the function and dynamic processes of an ecosystem; it reflects the circulation of matter and the energy transformations stemming from ecological relationships, and can be expressed by ecosystem service index [22]. The supply and consumption of ecosystem services have scale effects [23], and the ecosystem services that occur on different scales are interdependent [24]. This index broadens the spatial range of ecological assessment.

\subsection{Data Source}

The data used in the study was derived from the "China's first national ecosystem assessment (2000-2010)—Ecosystem Survey and Assessment of Liao River Basin" project, which contained 90-m resolution land use data; 250-m resolution 10-day NPP, LAI, and VC data; and 250-m resolution data on water source conservation, soil conservation, sand fixation, and carbon fixation services. Based on the land use data, we calculated the ecological integrated dynamic index [20] and landscape indexes (Fragment3.3).

\section{Results and Discussion}

\subsection{Ecosystem Structure and Changes in LRB during 2000-2010}

\subsubsection{The Spatial Distribution and Change of Ecosystem Structure}

The major types of ecosystems in LRB are arable land (40.69\%), forest land (30.89\%), and grassland $(19.33 \%)$. The LRB presents a gradual transition from northwestern to southeastern areas, with upstream regional grasslands and deserts, cultivated land in the middle and lower reaches, and forests in the southeastern hilly area (Figure 3). The forests are distributed mainly at high elevation areas in the eastern and western areas of the basin, the grasslands and deserts are located in the upstream region, and the cultivated lands are distributed around the main stream of the middle and lower reaches of the river in the plains of LRB, aggregating around the majority of towns in the basin.

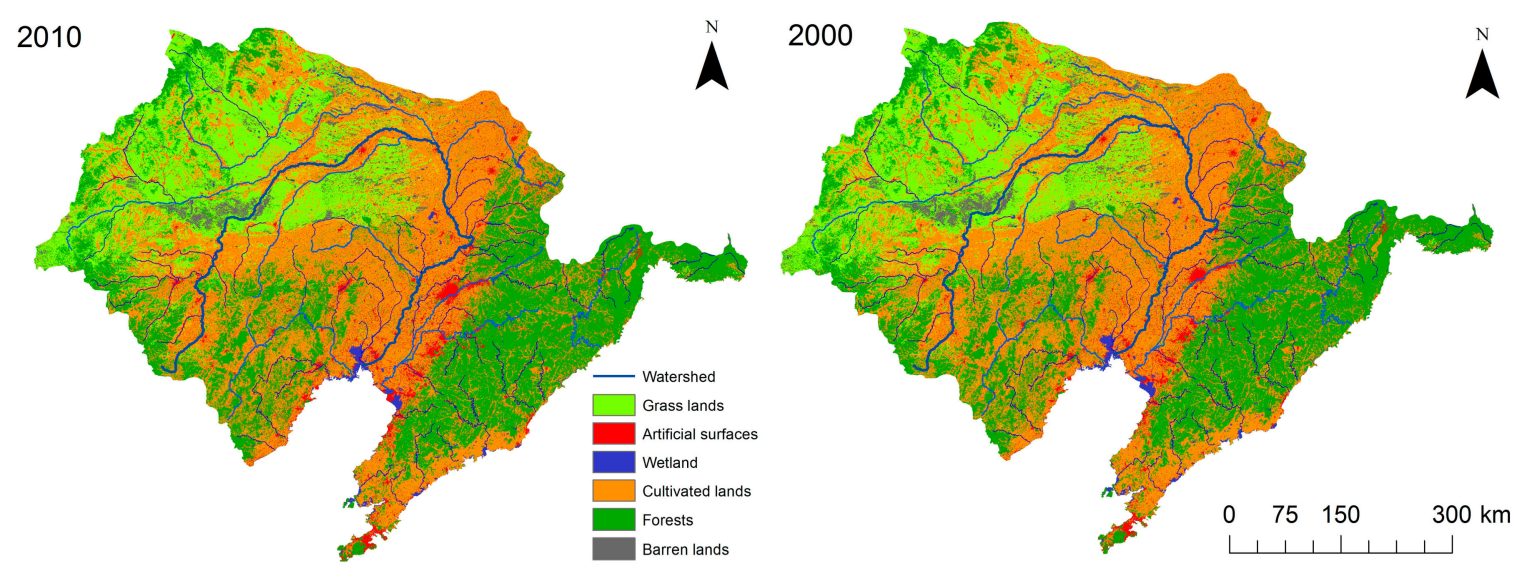

Figure 3. Ecosystem distribution of Liao River Basin in 2010 and 2000. 
The land use type transition presented a significant increase in the amount of artificial land and grasslands, and a decrease in the amount of cultivated land and wetlands, whereas the forest areas showed little change (Table 2). The most dramatic conversion was the transition of cultivated land to artificial land, especially in the Hun-Taizi River and in the downstream sub-basin. The upstream sub-basin showed an increase in artificial land and grasslands and a decrease in wetlands, with the conversion of grasslands and cultivated land to artificial land and desert, and cultivated land and wetlands transitioning to grasslands.

Table 2. Ecosystem type and transfer matrix of Liao River Basin in 2000-2010 (unit: km²).

\begin{tabular}{ccccccc}
\hline & Forest & Grassland & Wetland & Cultivated Land & Artificial Land & Other Type \\
\hline Forest & $96,770.08$ & 10.78 & 12.10 & 118.55 & 61.32 & 15.61 \\
Grassland & 24.28 & $59,590.77$ & 69.66 & 88.94 & 271.45 & 42.25 \\
Wetland & 27.29 & 164.00 & 5788.76 & 256.13 & 157.81 & 61.91 \\
Cultivated land & 165.02 & 322.91 & 242.08 & $127,213.70$ & 2030.85 & 135.63 \\
Artificial land & 4.99 & 4.06 & 9.80 & 20.29 & $12,581.02$ & 2.64 \\
Other type & 5.17 & 611.26 & 17.10 & 79.48 & 15.37 & 7063.64 \\
\hline
\end{tabular}

Changes to the whole basin and each sub-basin over the period showed that the variation over 2005-2010 was much more dramatic than that over 2000-2005.

The landscape changes manifested as decreases in the average patch sizes of forests, wetlands, and artificial land, as well as declines in landscape connectivity and increased fragmentation. However, the average patch sizes of grasslands and cultivated land increased. Further, fluctuations were noted for the average patch sizes of other land use types. For example, although the total forested area almost showed no change during 2000-2010, an obvious decrease was observed in the average patch sizes of forests.

\subsubsection{Ecological Quality}

The ecological quality assessment of LRB was performed by grading ecological quality and describing the changes in grasslands, forests, and cultivated land (Table 3). Further, based on the least square method (LSM), we calculated the ecological quality changes for the period and conducted significance tests (Figure 4).

Table 3. Ecological quality grading and area ratio in 2010.

\begin{tabular}{cccccccc}
\hline Ecosystem Type & Parameters & Lower & Low & Middle & High & Higher & Total \\
\hline \multirow{2}{*}{ Forest } & Areas $\left(\mathrm{km}^{2}\right)$ & $30,768.88$ & $23,412.31$ & $22,325.88$ & $20,401.25$ & 32.69 & $96,941.01$ \\
& Ratio $(\%)$ & 31.74 & 24.15 & 23.03 & 21.05 & 0.03 & 100.00 \\
\hline \multirow{2}{*}{ Grassland } & Areas $\left(\mathrm{km}^{2}\right)$ & $22,255.69$ & $37,359.56$ & 1076.94 & 7.31 & 0 & $60,699.5$ \\
& Ratio $(\%)$ & 36.67 & 61.55 & 1.77 & 0.01 & 0 & 100.00 \\
\hline \multirow{2}{*}{ Cultivated land } & Areas $\left(\mathrm{km}^{2}\right)$ & 4521.75 & $33,345.63$ & $85,380.75$ & 6806.19 & 28.25 & $130,082.57$ \\
& Ratio $(\%)$ & 3.48 & 25.63 & 65.64 & 5.23 & 0.02 & 100.00 \\
\hline
\end{tabular}

The grasslands distributed in the upstream region were poor quality, and the low and lower quality grasslands made up $98.22 \%$ of the total grassland areas. In further considering the quality changes, the southeastern area was found to be improving during the decade, but the improvement was not significant; the quality in the western region was found to be dropping significantly.

The cultivated land was widely distributed, located mainly over the middle and lower reaches of the main stream, and the quality was relatively high, while the quality of the cultivated land in the upstream region was shown to be the worst in the whole basin. The quality improved over the ten years, especially in a circular region in the upstream and downstream region, and the yield of arable land increased significantly. 


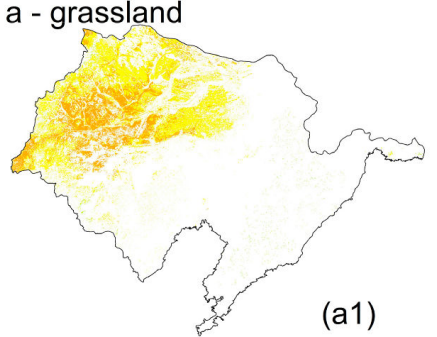

b - cultivated land

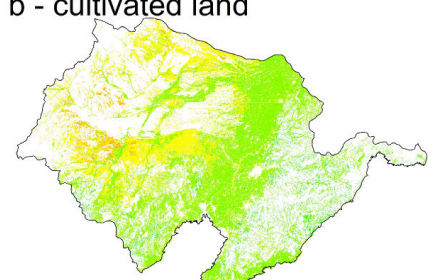

(b1)

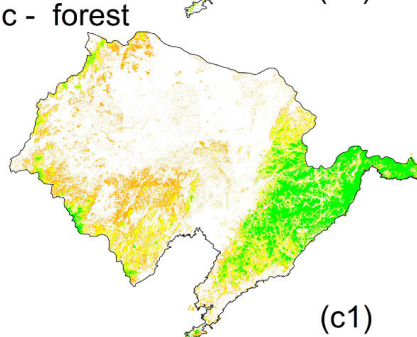

(c1)
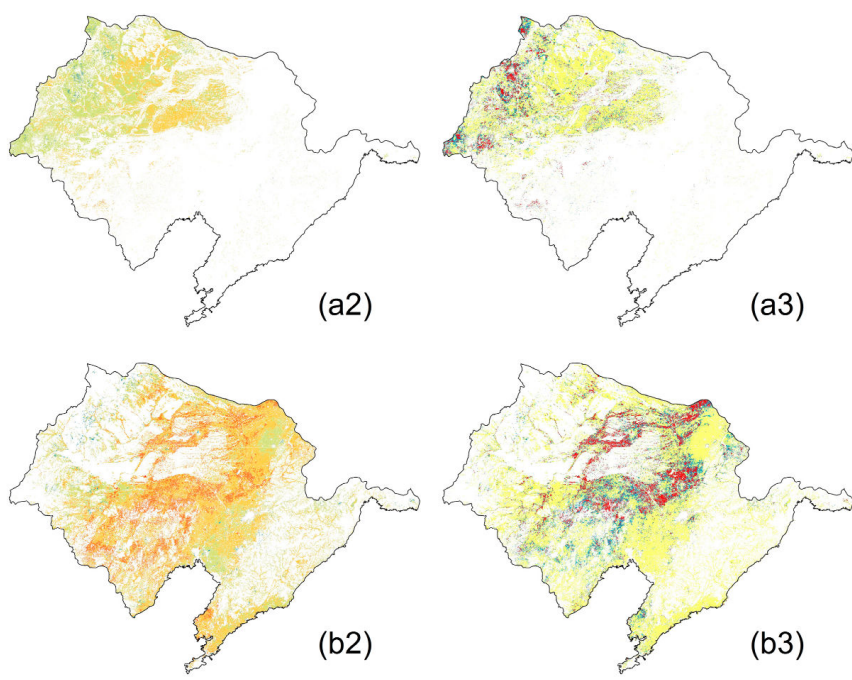

(b3)
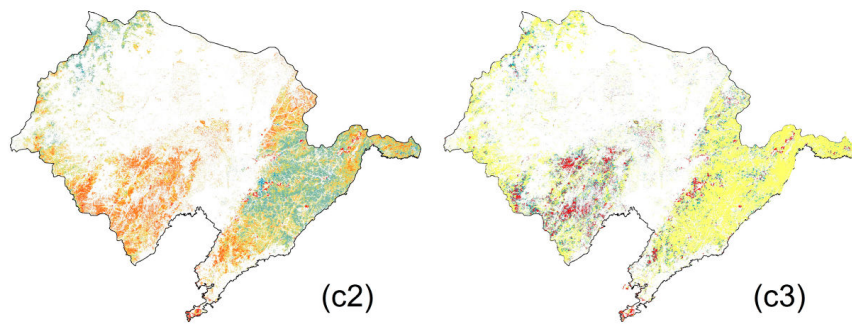

Ecosystem quality changes $(\mathbf{2 0 0 0 - 2 0 1 0 )}$
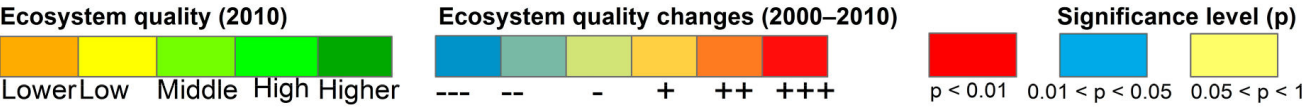

Figure 4. Ecosystem quality grading and the change in decade, (a) grassland; (b) cultivated land; (c) forest. Note: a1-a3 are representing the three dimensions of ecosystem quality in 2010, ecosystem quality changes in 2000-2010, and the significance of change for grassland; b1-b3 and c1-c3 are labeled for those three aspects in cultivated land and forest respectively.

The spatial distribution characteristics of the forest quality were obviously higher in the eastern region than in the western region. In considering annual variations, it was observed that higher-quality forests in the eastern region were lower than before, while the lower-quality forests in the western region showed significant improvement.

Overall, the ecological quality in the upstream region was in the worst condition of the whole basin. The quality of grasslands showed continuing deterioration, whereas that of the cultivated land along the main stream of the middle and downstream reaches was good and in the process of improving. The quality of the forests in the eastern region was high, and their decline during the decade was not significant; the quality of the forests in the western region was at a general level, but had improved significantly.

\subsubsection{Ecosystem Process}

The LRB provides an ecosystem service network with diverse services; from the perspective of dominant ecosystem services, the upstream region, with its widely distributed grassland-desert areas, provides the sand fixation and soil conservation services; the downstream region, with its concentrated distribution of cultivated land, offers food supply services and contributes to carbon fixation; and the western and eastern regions offer hydrological regulation and carbon fixation services (Figure 5). 

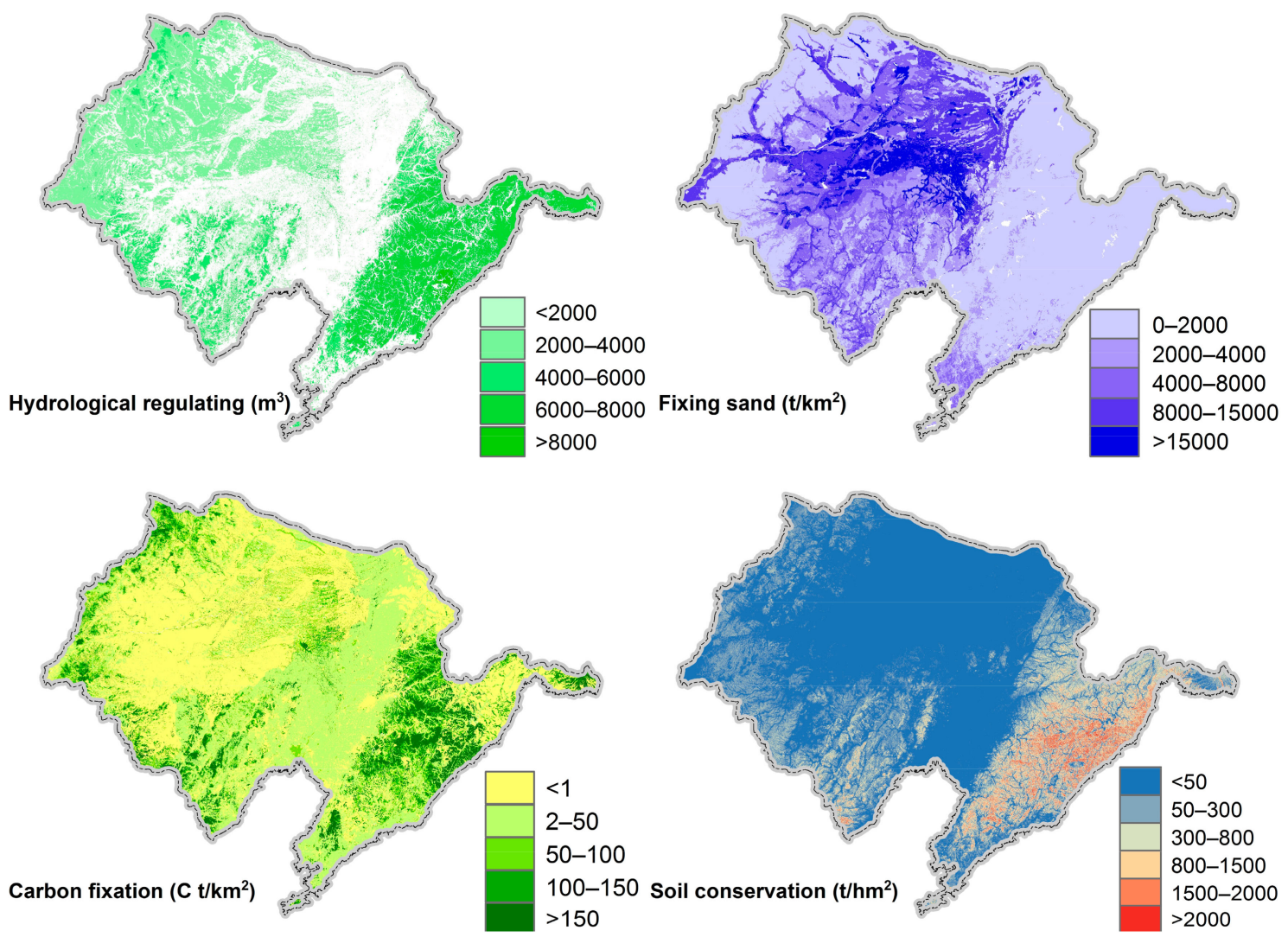

Figure 5. Distribution of dominant ecosystem service of Liao River Basin in 2010.

From the viewpoint of quantity of services provided, the eastern region offered the maximum services in the whole basin, while the species or quantity of services the upstream region provided were the minimum.

From the perspective of regional and national demands, as the western source of the main stream of the LRB and an important groundwater supply zone, the upstream region provided hydrological regulation and soil conservation services; at the same time, the services that the upstream region provided were also essential for the other sub-basins. The LRB also has two important national ecological functional zones located in the upstream region: the water supply and conservation zone and the Khorchin wind-breaking and sand-fixing zone [25].

After matching the supply with the demand of the basin ecosystem services, we can see that the upstream region is the critical region. It not only plays an important role for the sustainable development of the basin but also affects the national ecological security patterns. Presently, it still needs improvement in terms of ecosystem services in order to meet the developmental demands of both the basin and surrounding region.

\subsection{Ecosystem Security Pattern of LRB}

In the "structure-quality-process" analytical framework, there are three states in each criterion layer: improvement $(\uparrow)$, stabilization (-), and decline $(\downarrow)$. Thus, there are corresponding ecological

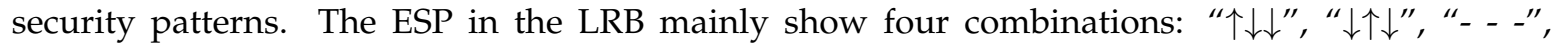

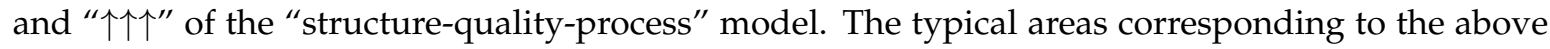
four combinations are the Upstream Region of Grassland Zone (URGZ), the Downstream Region of Cultivated Land (DRCZ), the Southeastern Forests Zone (SEFZ), and the Southwestern Forests Zone (SWFZ), respectively (Figure 6). The region divisions based on the ecosystem types above can also illustrate the major problems in each region. 


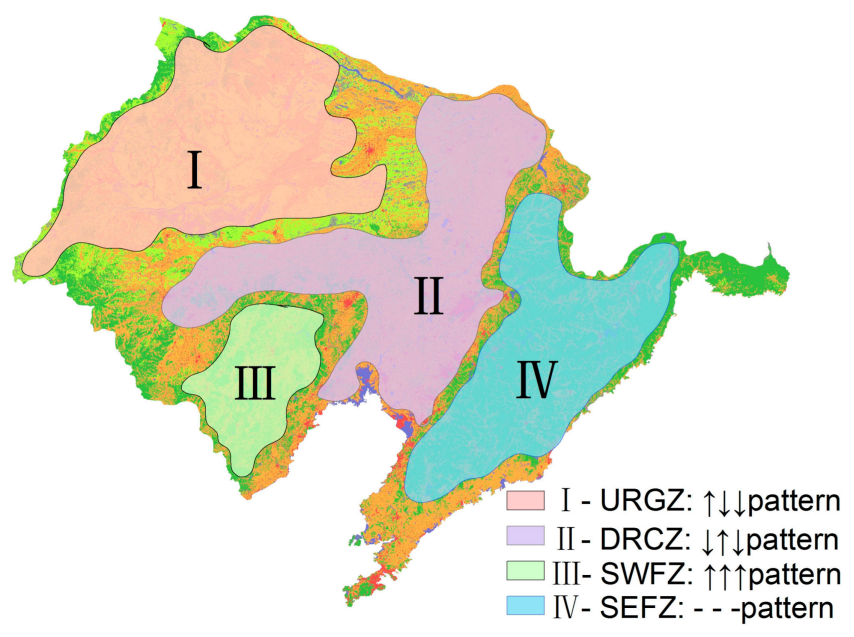

Figure 6. The typical areas of major ecological security patterns in Liao River Basin.

The typical "structure $(\uparrow)$-quality $(\downarrow)$-process $(\downarrow)$ " region is mainly distributed in the URGZ. Although the area of grassland expanded in the study period, the quality continued to decrease. The corresponding ecosystem services cannot meet the demands required by the development of either the upstream area of the whole basin in general. In addition to the impacts of climatic variations, disturbances caused by human activities are the dominant factor affecting the deterioration of grasslands. Unsustainable use and exploitation (e.g., overgrazing) causes grassland degradation. Uncontrolled ecosystem conversion also leads to grassland degradation, with the grasslands transformed to other land types typically coming from the good quality grassland regions, and the areas transformed to grasslands mainly coming from areas that were previously desert- the result of the latter means that the newly formed grasslands are often still in an unstable state. In general, the quality of the grasslands needs to be improved.

The typical "structure $(\downarrow)$-quality $(\uparrow)$-process $(\downarrow)$ " region is in the DRCZ, which is located in the Liao River Plain and is the best terrain in the basin for crop development. The grain yield of the cultivated area has been affected by artificial management and has had significant improvements. The ecosystem services in the region showed improved performance only in carbon fixation and poor performance in other ecosystem services.

The basin witnessed massive flooding during the studied decade, resulting in huge social and economic losses. There is wide area that the hydrological regulation less than $2000 \mathrm{~m}^{3}$, the low level of hydrological regulation services is another reason for the damage. Therefore, in order to balance development there is a need to consider not only improving agriculture management but also improving regional ecosystem services. The ecosystem services that need to be improved from a regional ES perspective are hydrological regulation and soil conservation, thus, the assessment result is mainly influenced by the selected indexes.

The typical "structure $(\uparrow)$-quality $(\uparrow)$-process $(\uparrow)$ " region is the SWFZ; although the ecological quality and services of this region cannot compare with the eastern forests zone, the indicators were improved during the decade of study, though its ecosystem management still requires strengthening.

The typical region of "structure (-)-quality (-)-process (-)" is the SEFZ; this region features the best quality and services in the basin and has been little affected by human activities.

In addition to the basic health and sustainability of ecosystem structure, quality, and processes, another key point of basin ecological security is the coordination of regional ecosystem services [26]. The coordination of regional ecosystem services is important in order to ensure that regional ecological services and environmental resources are rationally managed across the entire basin and each of the sub-basins. The fragile and critical areas of ecological security in LRB are URGZ and DRCZ. The ecological problems in these regions are evident, both from the perspective of the 
supply-and-demand of ecological services and from social and economic considerations, and threaten the ecological security of other areas as well. As such, the balance and coordination of ecological services in each of the sub-basins and regions need to be strengthened.

\section{Conclusions and Suggestions}

The main research conclusions of this study are summarized as follows:

(1) The major ecological change observed in LRB was the significant increase in artificial land $\left(2536.80 \mathrm{~km}^{2}\right)$ and grasslands $\left(1113.01 \mathrm{~km}^{2}\right)$, whereby the increases in artificial land mainly came from cultivated land $\left(2030.85 \mathrm{~km}^{2}\right)$ and the increases in grasslands mainly came from barren land $\left(611.26 \mathrm{~km}^{2}\right)$ and cultivated land $\left(322.91 \mathrm{~km}^{2}\right)$. The URGZ and the DRCZ were the regions observed to experience the most intense and variable changes. In analyzing land cover variations and ecological changes, the changes in 2005-2010 were observed to be more frequent and intense than those in 2000-2005. In considering the spatial differences of ecological quality, the quality of the upstream region was observed to be the worse in the basin, whereas the cultivated land in the downstream area was considered to be high quality, and both the SWFZ and the SEFZ were considered to be good quality. The upstream region was determined to be the key area for improving basin ecological quality.

(2) From an ecological services perspective, the upstream region (which contains two national ecological functional zones) was determined to be the priority area for basin service promotion, as the services offered in this area were lower and unable to satisfy regional developmental requirements.

(3) Based on the "structure-quality-process" assessment framework, the ecological security patterns

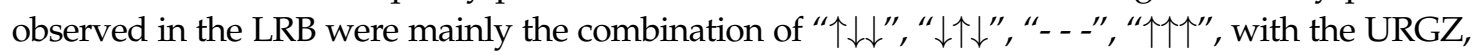
the DRCZ, the SWFZ, and the SEFZ as the typical representational regions, respectively. Although the basin has been classed into four security patterns, the coordination of each region still needs to be improved.

We proposed the following policy recommendations regarding the management of LRB.

(1) The ecological change in the basin demonstrate that the social and economic activities in the area still require an extension of their geographical ranges, and illuminates the need for human activities to prioritize the effective use and conservation of high quality lands (e.g., higher quality cultivated land and grassland). It suggests that the human activities in the area should be focusing on intensive-efficient development and reducing the expanding development. The upstream and the downstream regions should be the priority areas for the regulation of ecosystem structure and quality.

(2) The key areas for basin ecological security pattern optimizing are the URGZ and the DRCZ. The ecosystem services in these two regions were particularly unable to meet the demands of the regional sustainable development, and required an enhancement of ecosystem services conservation. In order to optimize the ecological security pattern in the URGZ, there is a need to improve the reconstruction of degenerated grasslands, to strictly manage grasslands, to enact grazing prohibition, to reuse farmland for grasslands, and so on. In order to ensure balanced development for the DRCZ, there is a need to improve the major ecosystem services of hydrological regulation and soil conservation, to reduce the impacts of natural disasters, and to enhance the ability of the ecosystem to resist disturbances. Simultaneously, the coordination of basin spatial development still needs to be improved.

(3) The "structure-quality-process" analytical framework for the LRB ecological security pattern considered the internal relationships of ecosystem structure and processes; essentially, the basic methods for building and maintaining the basin ecological security pattern are the promotion of basic ecological structures, the stabilization of ecological quality, and the strengthening of ecosystem services conservation. Therefore, these are the basic measures for ensuring a well-structured and ecologically secure ecosystem in terms of considering the ecosystem structure, quality, and processes. 
Author Contributions: C.Z. and C.W. conceived and designed the research; C.Z., C.W., Y.Y., and P.S. drafted the manuscript; J.L. and J.C. prepared figures; Y.Y. and C.Z. discussed the results and revised the manuscript. All authors read and approved the final manuscript.

Funding: This work was supported by “National Key Research and Development Program” (No. 2016YFC0502102) and "Survey and Assessment of National Ecosystem Changes between 2000 and 2010, China" (STSN-13-07).

Conflicts of Interest: The authors declare no conflict of interest.

\section{References}

1. Eigenbrod, F.; Bell, V.A.; Davies, H.N.; Heinemeyer, A.; Armsworth, P.R.; Gaston, K.J. The impact of projected increases in urbanization on ecosystem services. Proc. Biol. Sci. 2011, 278, 3201-3208. [CrossRef] [PubMed]

2. Elmqvist, T.; Fragkias, M.; Goodness, J.; Güneralp, B.; Marcotullio, P.J.; McDonald, R.I.; Parnell, S.; Schewenius, M.; Sendstad, M.; Seto, K.C.; et al. (Eds.) Urbanization, Biodiversity and Ecosystem Services: Challenges and Opportunities; Springer: Dordrecht, The Netherlands, 2013; ISBN 978-94-007-7088-1.

3. Wang, G.X.; Cheng, G.D.; Qian, J. Several problems in ecological security assessment research. Chin. J. Appl. Ecol. 2003, 14, 1551-1556.

4. Yu, G.M.; Feng, J.; Che, Y.; Lin, X.; Hu, L.; Yang, S. The identification and assessment of ecological risks for land consolidation based on the anticipation of ecosystem stabilization: A case study in Hubei Province, China. Land Use Policy 2010, 27, 293-303. [CrossRef]

5. Yu, G.M.; Zhang, S.; Yu, Q.W.; Fan, Y.; Zeng, Q.; Wu, L.; Zhou, R.R.; Nan, N.; Zhao, P.J. Assessing ecological security at the watershed scale based on RS/GIS: A case study from the Hanjiang River Basin. Stoch. Environ. Res. Risk Assess. 2014, 28, 307-318. [CrossRef]

6. Mei, Y. Study on Regional Land Use Change and Its Influence on Ecological Security. Ph.D. Thesis, Nanjing Agricultural University, Nanjing, China, 2009.

7. Yuan, L.; Susan, B.N. Assessing the relative severity of stressors at a watershed scale. Environ. Monit. Assess. 2004, 98, 323-349. [CrossRef] [PubMed]

8. U.S. Environmental Protection Agency. Watershed'96: Moving Ahead Together, Plenary Proceedings; 84-R-97-002; U.S. Environmental Protection Agency (EPA): Baltimore, MD, USA, 1996.

9. Committee on Watershed Management, National Research Council. New Strategies for American's Watersheds; The National Academies Press: Washington, DC, USA, 1999.

10. Zhao, J.; Liu, X.; Dong, R.; Shao, G. Landsenses ecology and ecological planning toward sustainable development. Int. J. Sustain. Dev. World 2016, 23, 1-5. [CrossRef]

11. Wang, Y.L. A study on landed of Weinan district. J. Nat. Resour. 1995, 4, 372-379.

12. Xiao, D.N. The formation and development of modern landscape science. Sci. Geogr. Sin. 1999, 4, 379-384.

13. Portieljeet, R.; Jacobsen, T.H.; Jensen, K.S. Risk analysis using stochastic reliability methods applied to two cases of deterministic. Water Res. 2000, 34, 153-170. [CrossRef]

14. Xiao, D.N.; Chen, W.B. On the basic concepts and contents of ecological security. Chin. J. Appl. Ecol. 2002, 13, 354-358.

15. Yu, K.J. Security Patterns and Surface Model in Landscape Ecological Planning. Landsc. Urban Plan. 1996, 36, 1-17. [CrossRef]

16. Yu, K.J.; Wang, S.S.; Li, D.H.; Qian, Q. Ecological baseline for Beijing's urban sprawl: Basic ecosystem services and their security patterns. City Plan. Rev. 2010, 34, 19-24.

17. Ren, H.J. Regional Ecological Security Pattern Evaluation and Construction. Master's Thesis, Beijing Forestry University, Beijing, China, 2011.

18. Wang, Y.L.; Zhao, Y.B.; Han, D. The Spatial structure of landscape ecosystem: Concept, indices and case studies. Adv. Earth Sci. 1999, 4, 235-241.

19. Xiao, D.N.; Brencang; Li, X.Z. Spatial ecology and landscape heterogeneity. Acta Ecol. Sin. 1997, $17,453-461$.

20. Xu, J.X.; Wang, J.Y.; Liang, T. Analysis of land use change in Taihu basin in the past 18 years. Geospat. Inf. 2009, 7, 48-51.

21. Schroevers, P.J. The need of an ecological quality-concept. Environ. Monit. Assess. 1983, 3, 219-226. [CrossRef] [PubMed]

22. Li, X.Y.; Ma, K.M.; Fu, B.J.; Niu, S.K. The regional pattern for ecological security (RPES): Designing principles and method. Acta Ecol. Sin. 2004, 5, 1055-1062. 
23. Kremen, C. Managing ecosystem services: What do we need to know about their ecology? Ecol. Lett. 2005, 8, 468-479. [CrossRef] [PubMed]

24. Ouyang, Z.Y.; Zheng, H. Ecological mechanisms of ecosystem service. Acta Ecol. Sin. 2009, 29, 6183-6188.

25. National Ecological-Functional Zoning; The Ministry of Environmental Protection of the People's Republic of China (MEP); The Chinese Academy of Sciences (CAS): Beijing, China, 2008.

26. Xie, X.F.; Wu, T.; Xiao, C.; Jiang, G.J.; Bian, H.J.; Ma, Y.; Chen, J.H. Ecological security assessment of the Dongyang River Watershed using PSR modeling. Resour. Sci. 2014, 36, 1702-1711. 